\title{
Pallidotomy Increases Cortical Inhibition in Parkinson's Disease
}

\author{
A. Strafella, P. Ashby, A. Lozano and A.E. Lang
}

\begin{abstract}
Background: Pallidotomy helps parkinsonian symptoms. We tested the hypothesis that this might be due to changes in inhibition in the motor cortex. Methods: We examined 15 patients with parkinsonism before and after posteroventral pallidotomy. Magnetic stimuli were delivered over the motor cortex, while subjects maintained a $30 \%$ maximum voluntary contraction of the contralateral first dorsal interosseus (FDI). Results: Weak stimuli inhibited voluntary muscle activity, while slightly stronger stimuli caused short latency facilitation from activation of the corticospinal neurons. After pallidotomy magnetic stimulation, at the threshold for the short latency facilitation, resulted in more inhibition than before. Conclusion: Pallidotomy increases cortical inhibition. This may be associated with improved control of movements.
\end{abstract}

\begin{abstract}
RÉSUMÉ: La pallidotomie augmente l'inhibition corticale dans la maladie de Parkinson. Introduction: La pallidotomie améliore les symptômes parkinsoniens. Nous avons évalué l'hypothèse selon laquelle cette amélioration pourrait être due à des changements de l'inhibition dans le cortex moteur. Méthodes: Nous avons examiné 15 patients atteints de parkinsonisme avant et après une pallidotomie postéroventrale. Une stimulation magnétique a été appliquée sur le cortex moteur alors que les sujets maintenaient une contraction maximum volontaire du premier interosseux dorsal contralatéral de 30\%. Résultats: Des stimulations faibles inhibaient l'activité musculaire volontaire, alors que des stimuli légèrement plus forts causaient une facilitation de la latence courte de l'activation des neurones corticospinaux. La stimulation magnétique, au seuil déterminé pour la facilitation de la latence courte, causait plus d'inhibition après la pallidotomie, qu'avant. Conclusions: La pallidotomie augmente l'inhibition corticale. Cette observation peut être associée avec une amélioration du contrôle des mouvements.
\end{abstract}

Can. J. Neurol. Sci. 1997; 24: 133-136

It has been postulated that parkinsonism results from the excessive inhibition of thalamocortical neurons by the globus pallidus internus. ${ }^{1}$ This inhibition may, in turn, affect the motor cortex. In methyl-4-phenyl-1,2,3,6-tetrahydropyridine (MPTP) treated monkeys the movement-related discharges of cortical neurons are more gradual and last longer than in normal monkeys and the reciprocal pattern of activity during flexion and extension movements is lost. ${ }^{2}$ In parkinsonian patients the inhibition of corticospinal neurons by weak transcranial stimulation is less than in normal subjects. ${ }^{3}$ Posteroventral pallidotomy improves parkinsonian symptoms. ${ }^{4}$ The aim of the present study was to determine whether this improvement was associated with changes in cortical inhibition.

\section{METHODS}

The study was approved by The Toronto Hospital Human Experimentation Committee and all subjects provided informed consent.

\section{Patients}

Fifteen patients with Parkinson's disease ( 6 female, 9 male) were studied. Their mean age was 55 years (range 46-70) and the mean duration of the disease was 11 years (range 2-20). All patients were studied before and 1-2 days after surgery.

\section{Recording technique}

Surface electromyographic (EMG) recordings were made with silver-silver chloride electrodes $1 \mathrm{~cm}$ in diameter taped over the belly of the first dorsal interosseous (FDI) and the base of the index finger. The EMG signal was amplified with a bandpass of $100 \mathrm{~Hz}$ to $10 \mathrm{kHz}$, monitored on an oscilloscope and led to an integrator (time constant $600 \mathrm{~ms}$ ). The integrator output was displayed on a second oscilloscope and the subject was instructed to maintain a $30 \%$ maximum voluntary contraction with the aid of the integrator display. The amplified signal was digitized (at $2 \mathrm{kHz}$ ), rectified and 50 sweeps of $250 \mathrm{~ms}$ were averaged by a computer. Each record was normalized to the mean of the $50 \mathrm{~ms}$ prestimulus segment. Periods of increased or decreased EMG in the poststimulus record were recognized where levels exceeded \pm 2 SD of the mean of the prestimulus portion of the recording. Latencies were measured to the preceding crossing of the mean. The area of a peak or trough was measured from the preceding to the following baseline crossings.

From the Division of Neurology, Playfair Neuroscience Unit, University of Toronto; and the Morton and Gloria Shulman Movement Disorders Center, The Toronto Hospital, Toronto.

RECEIVED AUGUST 13, 1996. ACCEPTED IN FINAL FORM JANUARY 7, 1997.

Reprint requests to: P. Ashby, The Toronto Hospital, Western Division, 8 EC-005, 399 Bathurst Street, Toronto, Ontario, Canada M5T 2S8 


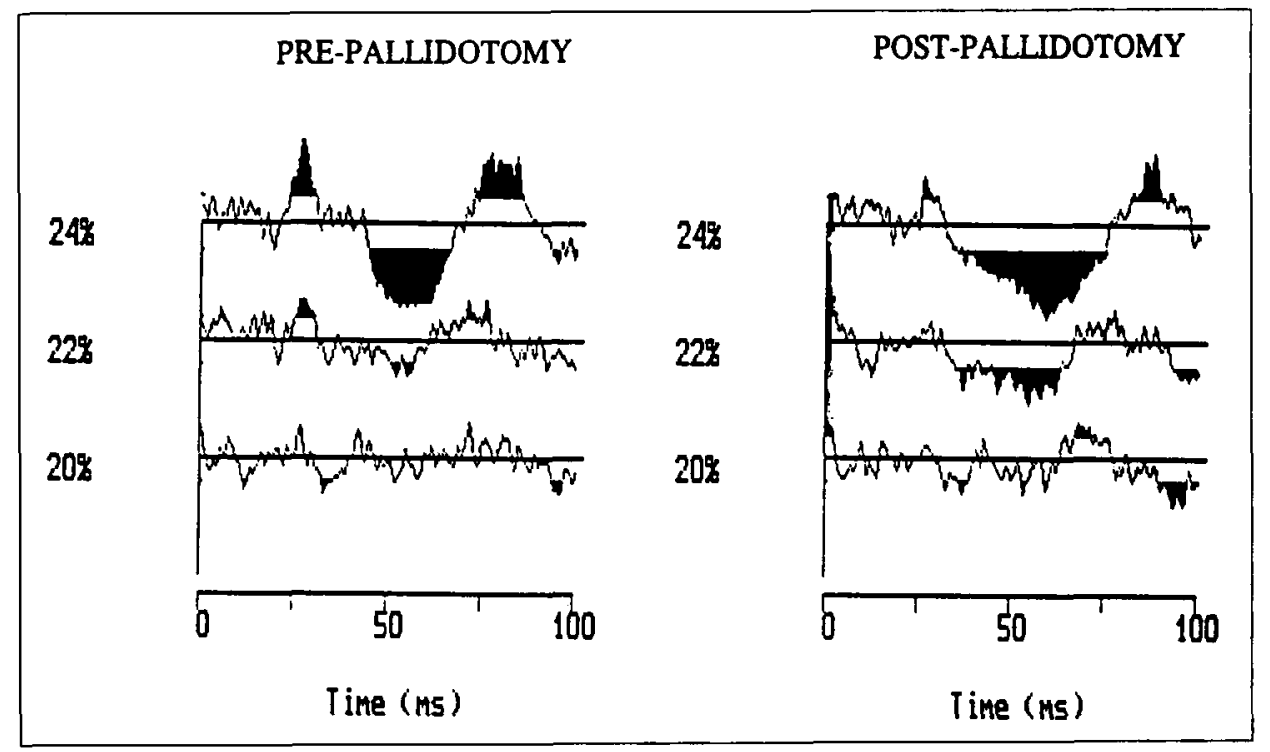

Figure 1: Effect of magnetic stimulation over the cortex on voluntary activity of the contralateral FDI of one subject before and after pallidotomy. Each trace represents the average of 50 sweeps of rectified EMG obtained while the subject maintained a $30 \%$ maximum contraction. The stimulus was given at time zero at the intensities indicated on the left (expressed as \% full scale of the stimulator). The dark areas indicate where the poststimulus trace was above or below the mean $\pm 2 S D$ of the $50 \mathrm{~ms}$ prestimulus zone (not shown). With stronger stimuli (e.g., 24\%) there is a small short latency $(\sim 25 \mathrm{~ms})$ facilitation resulting from the activation of corticospinal neurons. With weaker stimuli only inhibition may be seen (middle trace right). With even weaker stimulation no inhibition is seen (lowest traces). The magnitude of the inhibition at the threshold for the facilitation (middle trace left, top trace right) increases after pallidotomy.

\section{Stimulation technique}

Stimuli were delivered over the motor cortex contralateral to the studied limb with a Cadwell MES-10 magnetic stimulator fitted with a $9 \mathrm{~cm}$ circular coil. The coil was placed on the scalp at the point which gave a motor evoked potential at the lowest threshold, the posterior and lateral distances of this point from the vertex were recorded. For each patient, the center of the coil and the orientation were the same before and after pallidotomy. Stimuli were delivered at random intervals between 2 and 2.5 sec while the subject maintained a $30 \%$ contraction of the FDI. Various stimulus intensities, in increments of $2 \%$ of the full scale of the apparatus, were used to obtain the threshold intensity for the short latency facilitation and the later inhibition of EMG. The thresholds and magnitudes of the facilitation and inhibition were compared before and after surgery, using the paired Student's t test.

\section{Results}

\section{Prepallidotomy findings}

Magnetic stimulation over the motor cortex modulated tonic voluntary activity of the contralateral FDI in all 15 patients. The modulation at the lowest threshold (mean stimulus intensity = 20.4\%) was usually an inhibition. This had a mean latency of $33.5 \mathrm{~ms}$ and a mean area of 5.2 units. As the stimulus intensity was increased the inhibition became larger, and it was eventually preceded by a short latency facilitation (Figure 1). At the threshold for the facilitation (mean stimulus intensity $22.8 \%$, mean latency of $23.6 \mathrm{~ms}$, mean area of 6.0 units) the inhibition had a mean area of 9.8 units.

\section{Postpallidotomy findings}

Pallidotomy resulted in an immediate reduction in the patients' parkinsonian symptoms (reported separately). ${ }^{5}$ As before, of voluntary activity of the contralateral FDI produced by magnetic stimulation the modulation at the lowest threshold was usually an inhibition. This had a mean latency of $35.1 \mathrm{~ms}$ $(p>0.3)$ and a mean area of 9.1 units $(p<0.05)$; the mean threshold, $22.8 \%$, was slightly higher than before pallidotomy $(\mathrm{p}<0.005)$ (the statistical comparisons with prepallidotomy findings are given in brackets). At the threshold for the short latency facilitation [mean stimulus intensity $24.5 \%(\mathrm{p}<0.1)$, mean latency $24.6 \mathrm{~ms}(\mathrm{p}>0.3)$, and mean area of 4.6 units $(\mathrm{p}<0.1)$ ] the area of inhibition was significantly larger (mean $=18.5$ units) $(p<0.02)$, (Figures 1,2$)$.

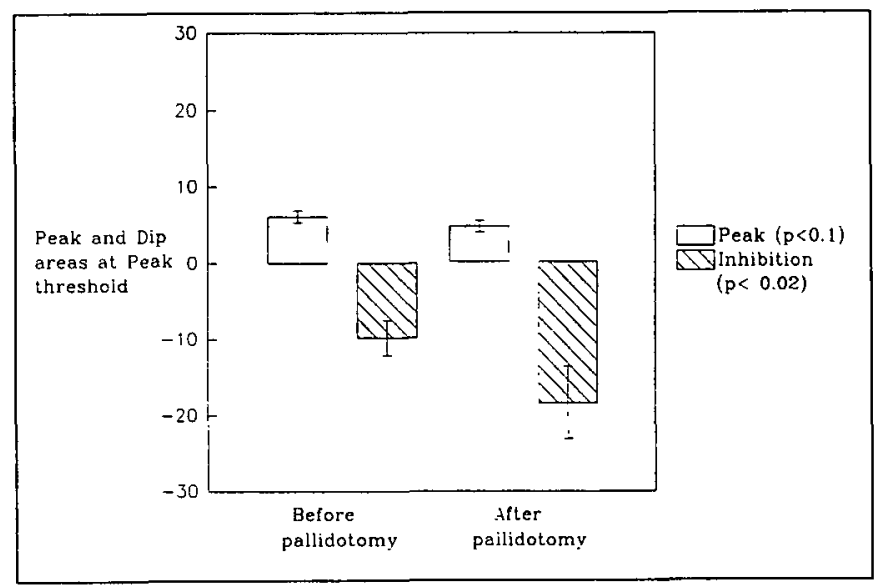

Figure 2: Mean areas of the short latency facilitation (hollow columns) and inhibition (filled columns) produced by magnetic stimulation at the threshold for the short latency facilitation before (left) and after (right) pallidotomy in 15 parkinsonian patients. 
Six of the patients were tested on therapy medication before and after pallidotomy and eight of the patients were tested on exactly the same medication (usually combinations of L-dopa carbidopa and pergolide) before and after pallidotomy. Both of these subgroups showed more inhibition at the peak threshold after pallidotomy, but because of the small number this was not significant for the group off medication.

\section{Discussion}

\section{Origin of inhibition produced by transcranial magnetic stimulation}

Transcranial magnetic stimulation probably excites corticospinal neurons both transynaptically and directly, while transcranial electrical stimulation and electrical stimulation over the brainstem appear to excite cortico-spinal axons directly. ${ }^{6.7}$ Magnetic stimulation over the motor cortex, that is too weak to produce short latency facilitation of voluntarily activated motor neurons (and, therefore, evidently too weak to induce descending volleys in corticospinal axons), causes inhibition of ongoing voluntary activity. ${ }^{8}$ This inhibition is presumed to take place in the cortex because: 1) cortical stimuli subthreshold for the production of a motor evoked potential inhibit for 5-6 ms the motor evoked potential produced by a second suprathreshold stimulus when the conditioning volley is magnetic ${ }^{3,9}$ but not if it is electrical $^{9}$ and because, 2) the excitability of spinal motoneurons (tested by a volley descending from the brainstem) is not depressed during this period. ${ }^{7.9}$ The inhibition, produced by magnetic stimulation, arises from the same area as the short latency facilitation ${ }^{7,8}$ and has lower threshold possibly because it arises from the more superficial layers of the cortex where the GABA-ergic inhibitory neurons predominate. ${ }^{7}$

\section{Cortical inhibition following pallidotomy}

Magnetic stimulation over the motor cortex at the threshold for activation of corticospinal neurons produces more inhibition of voluntary EMG after pallidotomy. This is not due to changes in motoneuron excitability (which was held constant) and is not due to impairment of corticospinal function (by, say, damage to corticospinal axons or local edema produced by the procedure) because there was no significant increase in threshold or latency of the short latency facilitation (Figure 2). A systematic error in coil placement is unlikely because measurements of coil site could be made within a few $\mathrm{mm}$. We conclude that magnetic stimulation, at the threshold of recruitment of corticospinal neurons, evokes proportionally more cortical inhibition after pallidotomy. The absolute threshold for the inhibition was slightly higher. This is, at present, unexplained. Ridding et al. ${ }^{3}$ tested cortical inhibition in parkinsonism with paired magnetic stimuli with the subjects at rest. The conditioning stimulus was below the threshold for evoking a descending corticospinal volley (tested during a voluntary contraction), the test stimulus sufficient to evoke a motor evoked potential at rest. There was less inhibition of the test response at condition-test intervals of 1-5 $\mathrm{ms}$ in parkinsonian patients than in normal subjects. This improved (although not significantly) after L-Dopa. Doudet et al. ${ }^{2}$ studied the behaviour of cortical neurons in monkeys rendered parkinsonian with MPTP. The spontaneous firing of neurons was unchanged but the proportion of neurons showing a

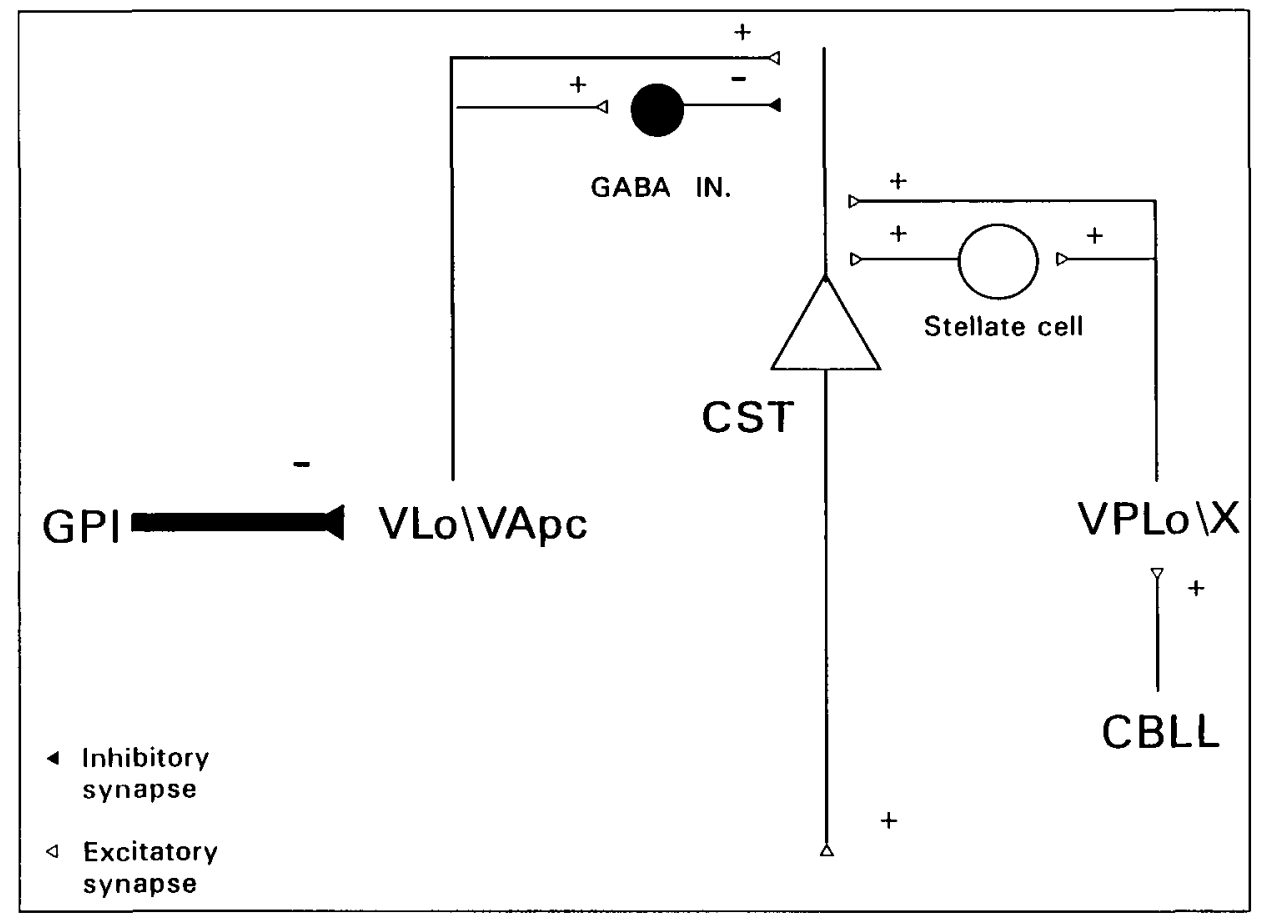

Figure 3: Postulated action of pallidotomy. Neurons of the "cerebellar" thalamus (VPLo, X) project to deep layers of motor cortex and produce facilitation of corticospinal neurons. Neurons of the "pallidal" thalamus (VPLo, VAPC) project to the superficial layers of motor cortex where they synapse with dendrites of inhibitory interneurons "focusing" motor output (Nakano et al. 1992). Parkinsonism is attributed to excessive inhibition of "pallidal" thalamo cortical neurons from GPI which would result in less cortical inhibition. Pallidotomy (a lesion of GPI) would increase cortical inhibition; thalamotomy (a lesion of VPLo) reduce cortical facilitation. (GABA IN = Gabaergic inhibition.) 
reciprocal pattern of discharge during flexion and extension movements was greater $(49 \%)$ in normal monkeys than in MPTP treated monkeys (18\%). This could be related to loss of cortical inhibition: focal injections of the GABA antagonist bicuculliline into the cortex of awake behaving monkeys augment the activity of movement related cortical neurons and reduce their directionality. ${ }^{10}$

\section{Hypothesis to explain the effects of pallidotomy}

Ridding et al. ${ }^{3}$ proposed that the basal ganglia might preset the excitability of cortical circuits by controlling cortical inhibitory neurons. Nakano et al. ${ }^{11}$ examined the projections from the motor thalamus to the motor cortex in monkeys and reported that the neurons of the cerebellar thalamic nucleii (VPLo) projected to the deep layers of the motor cortex, while neurons of the pallido thalamic nucleii (VLo) projected to the superficial layers. They suggested that the deep projections could have powerful facilitatory effects on cortical neurons while the projections to the superficial layers might synapse with apical dendrites and superficial inhibitory interneurons and exert a "focusing" effect on pyramidal cell discharge. If the findings of Nakano et al. ${ }^{11}$ apply to humans, the hypothesis of Ridding et al. ${ }^{3}$ could be extended as follows (Figure 3). In parkinsonism there is excessive inhibition of thalamo cortical neurons and thus less of the cortical inhibition needed to "focus" movements. The balance can be restored either by decreasing the inhibition from the pallidum (L-dopa, pallidotomy) or by decreasing the facilitation from the cerebellar thalamus (thalamotomy).

\section{ACKNOWLEDGEMENT}

We thank the Medical Research Council of Canada (Grant \#6727, PA).

\section{REFEREMCES}

1. De Long MR. Primate models of movement disorders of basal ganglia origin. Trends Neurosci 1990; 13: 281-285.

2. Doudet DJ, Gross C, Arluison M, Bioulac B. Modification of precentral cortex discharges and EMG activity in monkeys with MPTP-induced lesions of DA nigral neurons. Exp Brain Res 1990; 80: 177-188.

3. Ridding MC, Inzelberg R, Rothwell JC. Changes in excitability of motor cortical circuitry in patients with Parkinson's disease. Ann Neurol 1995; 37: 181-188.

4. Laitinen LV, Bergenheim T, Hariz MI. Leksell's posteroventral pallidotomy in the treatment of Parkinson's disease. J. Neurosurg 1992; 76: 53-61.

5. Lozano AM, Lang AE, Glavez-Jimenez N, et al. Effect of Gpi pallidotomy on motor function in Parkinson's disease. Lancet 1995; 346: 1383-1387.

6. Day BL, Dressler D, Maertens de Noordhout A, et al. Electric and magnetic stimulation of human motor cortex: surface EMG and single motor unit response. J Physiol 1989; 412: 449-473.

7. Davey NJ, Romaiguere P, Maskill DW, Ellaway PH. Suppression of voluntary motor activity revealed using transcranial stimulation of the motor cortex in man. J Physiol 1994; 477: 223-235.

8. Hallett M. Transcranial magnetic stimulation. Negative effects. In: Fahn S, Hallett M, Luders HO, Marsden CD, eds. Negative Motor Phenomena. Advances in Neurology. Philadelphia: Lippincott-Raven Publishers, 1995: 107-113.

9. Kujirai T, Caramia MD, Rothwell JC, et al. Corticocortical inhibition in human motor cortex. J Physiol 1993; 471: 501-519.

10. Matsumura M, Sawagushi T, Kubota K. GABA-ergic inhibition of neuronal activity in the primate motor and premotor cortex during voluntary movement. J Neurophysiol 1992; 68: 692-702.

11. Nakano $K$, Tokushige $A$, Kohno $M$, et al. An autoradiographic study of cortical projections from motor thalamic nuclei in the macaque monkey. Neurosci Res 1992; 13: 119-137. 